\title{
Research on the Red Tourism Translation from the Perspective of Skopos Theory
}

\author{
Yanmei Liu \\ School of Foreign Languages, Yan'an University
}

\begin{abstract}
Based on Skopostheorie, this paper elaborates on the basic elements in the translation process of tourist scenic media texts from the perspective of linguistics, such as, audience, text, translator, noise and feedback. In addition, in view of the substantial differences between Chinese and foreign cultures, especially the technical problems in the translation of Chinese revolutionary cultural scenic media texts caused by cultural differences, the author studies the translation of red tourism culture from the perspective of Skopos theory and strategies for cross cultural translation of color tourism resources based on the research experience in cross-cultural translation of red tourism.
\end{abstract}

Keywords—Red tourism; Scenic publication texts; Intercultural translation

\section{INTRODUCTION}

Red tourism mainly refers to a new type of theme tourism which takes the memorial of the people's revolution led by the Communist Party of China, the memorial place and the revolutionary spirit inherited by it as tourism resources and combines the revolutionary traditional education with the promotion of the development of tourism industry.

With the continuous development of China's economy and the increasing economic capacity in recent years, many people in western countries want to understand the internal driving force of China's development. Since the reform and opening up, our country has carried out the cultural strategy of "going out". Since the 18th National Congress of the CPC, the "institutional self-confidence" and "cultural self-confidence" advocated by the whole society are not only reflected in the dissemination of material culture, but also in the focus and direction of our spiritual and cultural construction. In order to make foreign tourists understand the achievements of China today, the Red Revolution and red culture are inseparable. Therefore, when they visit some of China's red tourist attractions, the English translation of the scenic spots will become the main carrier of cultural transmission. According to the author's investigation, there are many errors in the translation of some English versions of tourist attractions, such as: spelling and grammatical errors, mistranslation of place names, mistranslation of cultural information, Chinese-style English translation, non-standard diction, inconsistent translation names, etc. Some serious errors in translation may lead to misunderstandings among foreign tourists and have a certain impact on the international reputation of China's red tourism [1-2].
The inaccuracy of translation will not only affect the quality of the red scenic spots, but also bring some negative effects on the promotion and development of the tourism industry, and even affect the overall image of the red scenic spots and even the national image of China. The landscape text translation not only carries the spread of the red revolutionary culture [3], but also links and bridges the cultural exchanges between China and foreign countries. How to find the breakthrough point and balance point of translation in the differences between the two cultures?

\section{THE ELEMENTS AND BASIC REQUIREMENTS FOR THE TRANSLATION OF TOURISM ENGLISH TEXTS FROM THE SKOPOSTHEORIE}

From Catherine Rice's first introduction of functional categories into translation criticism to Christina Nord's comprehensive summary and perfection of functionalist theory, it has been emphasized in the study and application of Skopostheorie that the primary principle followed by all translation activities is the "Skopostheorie", so the most important factor in the process of translation is reversion. The purpose of translation and the effect of translation must be determined by the whole process of translation (Nord, 2001:124). The purpose and ultimate effect of translation depend on the readers, including their cultural background, expectations for the translation, their appeal, social knowledge and communicative needs. There are many aspects involved in the text of Red Tourism Scenic Spots, such as: historical books, humanistic community, local customs, modern social background, poetry, character style. As an "advocative" style, it has the function of transmitting information and inducing function. Therefore, the premise of landscape text translation is to convey information, and its purpose is to induce actions.

\section{A. The elements of scenic publication text translation}

In the translation of tourist scenic spots, there are five main factors: audience, text, translator, noisy, feedback and so on. These factors are interrelated and interact with each other. They are an integral part of an organic whole. The process of translation is also the result of the organic combination and interaction of these factors.(1) Audiences, as an active information receiver, disseminators of information reprocessing and feedback sources of communication activities play an important role in the translation activities. (2) Text: In terms of textual information, comparative study of language is very important, because tourism translation and 
communication are produced in two languages. In describing the tourist attractions, most of the styles of English tourism are simple and logical. (3) Translators: They should also be concerned about the translator's role in the process of translating information. As a gatekeeper, the translator should give full consideration to the differences between the original author and the target reader. (4) Noisy: It is a process of reducing the uncertainty of target readers' understanding of the content of the original text. (5) Feedback: It refers to the process of sending all or part of the output information back to the input of the system and affecting the re-output of the information.

\section{B. Requirements for the translation of tourism scenic publication texts}

The Skopos Principle plays a very important role in the translation activities. As a decision-making process, the translation process has a strong purposefulness. Therefore, in order to make Skopostheorie the basic theoretical basis for guiding the translation of scenic spots in red tourism areas, the following two basic requirements must be followed: (1) translators should follow the cultural background and communication habits of the target language users, specify different translation objectives according to different users, and Choose appropriate translation methods according to different language environments and translation purposes. (2) Translators can exert their creativity and subjectivity in the process of translation, which is the main feature of Skopostheorie in guiding Chinese Cross-text translation. This theory, on the one hand, shows that translation should ensure that the ideological tenet can be changed in an all-round way, even if the meaning expressed in a foreign text is consistent with that expressed in a Chinese text. (3) Equivalence of translation forms should be emphasized. As a kind of applied culture, the equivalent translation of functional cultural information becomes particularly important.

In a word, we should not simply apply various translation theories in the whole process of translation, but the form of translation should be decided by the ultimate purpose of translation. Due to the differences in the ways of expression between Chinese and English, the theory of focusing solely on translation may result in inaccurate communication of cultural information.

\section{THE CHARACTERISTICS OF RED TOURISM PUBLICATION TEXT IN THE PROCESS OF TRANSLATION}

The translation of red tourism scenic spots refers to the translation of tourism scenic spots, but because of its crosscultural and stylistic features, it is different from the translation of general tourism English.

\section{A. Cross cultural characteristics}

In tourism English translation, translation itself is the exchange of two languages and two cultures, so the translation of scenic spots in red tourism is also for better communication and communication between people in different cultural backgrounds. In the process of communication, the linguistic differences between people mainly take translation as a means of communication. Color tourism translation is a crosslinguistic, cross-social, cross-cultural, cross-temporal and cross-psychological communicative activity, which can be divided into two types: interpretation and translation. The texts to be translated mainly include: the explanatory contents of the introduction, the names of the scenic spots, the tourist publicity materials, the tourist guides, the road signs, the names of places, the tourist maps, the names of hotels, the names of dishes, etc. Meanwhile, they also include many words of cultural connotations, such as literature, art, philosophy and religion. Characteristic architecture, clothing and folk custom. It can be seen that the translation of red tourism contains many cultureloaded words, which reveal the revolutionary cultural atmosphere of our country.

There are many cultural differences in the translation of red tourism culture. Especially in the translation of historical stone inscriptions, inscriptions, poems and names of scenic spots in Chinese revolutionary relics, the unique characteristics of the revolutionary culture of the Chinese nation at a particular period of time should be highlighted. In the translation of such scenic spots, the text of scenic spots plays a very important role in spreading the excellent revolutionary culture of China. Appropriate scenic spots can make tourists feel the profound Chinese revolutionary culture and the rich cultural landscape. So how to make foreign tourists in different cultural atmosphere understand and like red tourism, it is necessary to consider the cultural differences in the context of translation strategies, when foreign tourists understand the translation of cultural transmission. Although the translated text of red tourism cannot be expressed in the same way as other literary works and scientific and technological literature according to the fixed grammatical structure and expression mode, it has a very strong practicability and purposefulness. Therefore, the purpose and effect of red tourism translation should be balanced comprehensively to ensure that it can give explanations to foreign visitors. Correct cultural atmosphere and rich cultural connotation.

It can be seen that cross culture is a very prominent feature in the translation of red tourism landscape texts.

\section{B. Stylistic features}

There are many differences in cultural backgrounds, modes of thinking and values between different countries, so there are great differences in stylistic styles between English and Chinese cultural backgrounds. From the perspective of English tourist materials, the introduction of tourist attractions is simple in style, rigorous in logical thinking, and concise in wording, which can achieve the purpose of intuitive expression, highlighting the key points, and easy to understand. From the perspective of the expression of Chinese red tourism materials, most of the red tourism materials are more magnificent and literary, the text is very concise, compact, euphemistic and 
implicit, the translators are better at using metaphor, antithesis, parallelism and other techniques. In addition, the translation of red cultural tourist attractions usually involves the translation of some ancient poetry, revolutionary documents, and important speech documents. Most foreign tourists who come to visit China may not understand the revolutionary history and culture of China. If they translate it in a rigid way, they will feel obscure and difficult to understand. This requires translators to have a thorough understanding of the tourist materials, which make certain processing so as to convey the essence of the tourist materials to the tourists.

It can be seen that the style of the translation of the red tourism scenic spots is still different from that of foreign tourist attractions. It has its own cultural characteristics. It is necessary to fully understand the text of the scenic spots in order to translate reasonably rather than simply translate it literally.

\section{StRATEgIES OF CROSS CULtURAL TRANSLATiON OF RED TOURISM SCENIC PUBLICATION TEXTS}

\section{A. Respect the theme of landscape publiction text and allow the translator to play a dominant role}

Respecting the theme of landscape text means that the translator needs to understand and comprehend the main idea of the original text in the process of translation, and employ various means of translation fully and accurately to express the main idea of the original text, which can ensure the original meaning does not deviate from the original meaning. The socalled translator's dominant role is that the translator will carry out the subjective initiative throughout the whole process of translation. This initiative requires that the translator should not be a slave to the original text in the process of translation and carry out mechanical and regular translation work, but should actively study the original text and comprehend it. Basically speaking, the original text is properly processed so that the translated text has its own unique characteristics. The translator is not only a translator, but also a participant in cultural transmission. The translator himself should have a strong ability of cross-cultural communication, and be able to understand and master the way of communication under different cultural backgrounds. Translators should be able to choose appropriate expressions from the cultural perspective of the audience to convey the cultural meaning of the red scenic spots accurately and clearly, and stimulate the interest of tourists in continuing to travel and recommend to others simultaneously.

\section{B. Take the audience's cultural background as the premise and adopt the method of transliteration and free translation}

For the red scenic spots, literal translation or full free translation will make the scenic spots or scenic spots text lose its original cultural significance and value. For names of people, places or dynasties, direct translation from an objective point of view is acceptable, but for some poetry, revolutionary events and allusions, the use of direct translation will make foreigners feel obscure and boring. At the same time, due to the lack of understanding of Chinese poetry, allusions and revolutionary events, foreign tourists often have a sense of ignorance about the literal translation of English texts. In this case, the translator should extract the main idea of the Chinese text, change it to the cultural background of foreign audiences, and introduce it to tourists in an easy-to-understand way so that they can understand its meaning and origin text more deeply, so that they can feel the red culture of China emotionally and conceptually. In this way, tourists can be constantly stimulated to explore the Chinese red culture interest, so as to eventually achieve the dissemination of Chinese culture, enhance national sense of pride.

In the process of translation, the text of scenic spots and scenic spots cannot be translated directly, nor can it be translated wholly in the way of westernization. Both of these translation methods are poor and inadequate in expressing China's regional information and extensive red cultural information. Therefore, the combination of transliteration and paraphrasing can be adopted in the translation of scenic spots, so as to ensure that foreign tourists can understand the information conveyed by the scenic spots and preserve the unique characteristics of Chinese red tourism culture. Translation can neither be too lengthy nor too simple. If it is too lengthy, tourists will be bored, unwilling to spend time reading, and cannot stimulate the interest of tourists to continue to watch and explore. If it is too simple to make tourists feel perfunctory or despised, psychological conflict will also lose interest and enthusiasm to explore Chinese red culture. This will result in the loss of Chinese culture through tourism.

\section{Take the purpose of translation as the starting point and adopt the translation method of increase or decrease}

Under certain circumstances, in order to facilitate tourists to understand the text of scenic spots in red tourism, we can make appropriate adjustments on the basis of the Chinese text, and adopt the method of adding or subtracting translation. If we simply translate the Chinese text rigidly, we will often give foreign audiences a sense of ignorance or misunderstanding, which is equivalent to artificial barriers to cultural transmission. The audiences lose interest in visiting because they do not understand the meaning of the text, forming a fragment of cultural understanding and blind area. Therefore, when translating, the translator can delete some sentences which are difficult to be understood by the audience. At the same time, he should add some easy-to-understand and easy-to-translate sentences on the basis of maintaining the original cultural and historical meaning of the Chinese text, and then translate them in a coherent context. Such a translation not only respects the original meaning of the original text, but also enables the audience to understand it. It is easy to accept and understand, it is to kill two birds with one stone and make the best of both worlds. In a word, in the translation of the text of the Red Tourism Scenic Spot, the method of adding or decreasing translation can meet the needs of the audience's thinking mode and cultural aesthetic viewpoints, and achieve the purpose of translation. 


\section{CONCLUSION}

In a word, the main purpose of the translation is to spread Chinese red culture, attract more foreign tourists to visit China's rich red resources, and arouse tourists interest to explore the history of the Chinese revolution. In the process of translating red tourism materials, we should take the characteristics of red culture, the special cultural background, thinking mode and aesthetic viewpoints of the audience into account. Based on Skopos theory, translators should adopt various of translation strategies to diminish cultural differences and achieve the goal of spreading Chinese red culture and providing high-quality tourism services to tourists around the world. With the advent of globalization and cultural globalization, tourism resources have become a kind of external resources. Red tourism, as a tourism resource with Chinese characteristics, should be guided by the purpose of cross-cultural communication, constantly improve its translation strategies of tourism texts, so that foreign tourists can recognize China's development from the red culture. With the advent of globalization and cultural globalization, tourism resources have become a kind of external resources. Red tourism, as a tourism resource with Chinese characteristics, should be guided by the purpose of cross-cultural communication, constantly improve and improve its translation strategies of tourism texts, so that foreign tourists can recognize China's development from the red culture.

\section{REFERENCES}

[1] An Analysis of the Present Situation and Improvement of the English Translation of Scenic Spots in Red Tourism from Skopostheorie: A Case Study of the Old Revolutionary District of Hongan, Hubei Province. Journal of Xialin Chifeng University (Science Education Edition). 2011 09-25. (In Chinese)

[2] Tourism translation from the perspective of communication. Zhang Zhifang. Examination weekly. 2007-11-26. (In Chinese)

[3] Cross cultural communication in tourism translation from the perspective of Skopos theory. Huang Chuang. Journal of Shaoguan University. 2008-11-15. (In Chinese) 